\title{
Functional and structural connectivity of frontostriatal circuitry in Autism Spectrum Disorder
}

\author{
Sonja Delmonte ${ }^{1,2}$, Louise Gallagher ${ }^{1 *}$, Erik O'Hanlon ${ }^{3}$, Jane McGrath ${ }^{1,2}$ and Joshua H. Balsters ${ }^{2,4}$ \\ 1 Department of Psychiatry, Trinity College Dublin, Dublin, Ireland \\ 2 Trinity College Institute of Neuroscience, Trinity College Dublin, Dublin, Ireland \\ ${ }^{3}$ Department of Psychiatry, Royal College of Surgeons, Dublin, Ireland \\ ${ }^{4}$ Neural Control of Movement Lab, Department of Health Sciences and Technology, ETH Zurich, Zurich, Switzerland
}

\section{Edited by: \\ Ralph-Axel Müller, San Diego State \\ University, USA}

\section{Reviewed by:}

Xiaobo Li, Albert Einstein College of Medicine, USA

Adriana Di Martino, New York

University Langone Medical Center, USA

\section{*Correspondence:}

Louise Gallagher, Department of

Psychiatry, Trinity College Dublin,

College Green, Dublin 2, Ireland

e-mail: Igallagh@tcd.ie
Abnormalities in frontostriatal circuitry potentially underlie the two core deficits in Autism Spectrum Disorder (ASD); social interaction and communication difficulties and restricted interests and repetitive behaviors. Whilst a few studies have examined connectivity within this circuitry in ASD, no previous study has examined both functional and structural connectivity within the same population. The present study provides the first exploration of both functional and structural frontostriatal connectivity in ASD. Twenty-eight right-handed Caucasian male ASD (17.28 \pm 3.57 years) and 27 right-handed male, age and IQ matched controls (17.15 \pm 3.64 years) took part in the study. Resting state functional connectivity was carried out on 21 ASD and control participants, and tractography was carried out on 22 ASD and 24 control participants, after excluding subjects for excessive motion and poor data quality. Functional connectivity analysis was carried out between the frontal cortex and striatum after which tractography was performed between regions that showed significant group differences in functional connectivity. The ASD group showed increased functional connectivity between regions in the frontal cortex [anterior cingulate cortex (ACC), middle frontal gyrus (MFG), paracingulate gyrus (Pcg) and orbitofrontal cortex (OFC)], and striatum [nucleus accumbens (NAcc) and caudate]. Increased functional connectivity between ACC and caudate was associated with deactivation to social rewards in the caudate, as previously reported in the same participants. Greater connectivity between the right MFG and caudate was associated with higher restricted interests and repetitive behaviors and connectivity between the bilateral Pcg and NAcc, and the right OFC and NAcc, was negatively associated with social and communicative deficits. Although tracts were reliably constructed for each subject, there were no group differences in structural connectivity. Results are in keeping with previously reported increased corticostriatal functional connectivity in ASD.

Keywords: Autism Spectrum Disorder, connectivity, frontostriatal, striatum, fMRI, DTI, social reward

\section{INTRODUCTION}

Frontostriatal circuitry plays an important role in social motivation, which is postulated to underlie deficits in social interaction and communication in Autism Spectrum Disorder (ASD) (Dawson et al., 2005, 2012; Chevallier et al., 2012). Aberrant BOLD responses to social rewards have been reported in a number of studies of social reward processing in ASD, providing support for this hypothesis (Scott-Van Zeeland et al., 2010; Dichter et al., 2011; Delmonte et al., 2012; Kohls et al., 2012a,b). Studies of reward and executive function also implicate frontostriatal circuitry in repetitive behavior symptoms (Langen et al., 2011a,b; Dichter et al., 2012). Additionally, functional abnormalities in frontostriatal circuitry have been reported during higher-order cognitive and sensorimotor tasks (Schmitz et al., 2006; Takarae et al., 2007; Scott-Van Zeeland et al., 2010). Therefore, abnormalities in frontostriatal circuitry may underlie the two core deficits in ASD; social interaction and communication, and restricted interests and repetitive behaviors (Langen et al., 2011a,b;
Chevallier et al., 2012; Dichter et al., 2012), as well as other cognitive and motor impairments that are associated with ASD.

Frontostriatal circuitry plays a key role in a number of different processes such as emotion, motivation, cognition, and the control of movement, which work in tandem to execute goal directed behaviors (Haber, 2003). The functional variety of frontostriatal circuits can be explained to some extent by examining its cortical inputs. Frontostriatal circuits have a looped structure with cortical inputs feeding information to the striatum which in turn projects back to the cortex via the thalamus (Alexander et al., 1986, 1990). Primate studies have shown that frontostriatal projections are arranged into a number of parallel, integrative loops, with each loop comprising discrete regions of striatum, cortex, globus pallidus, substantia nigra and thalamus, and subserving specific motor, cognitive, or affective function (Groenewegen et al., 1999, 2003; Haber and Knutson, 2009). Information is primarily channelled from ventral limbic, to more dorsal cognitive and motor loops such that action decision-making is 
influenced by motivation and cognition (Middleton and Strick, 2000; Haber, 2003). Diffusion tensor imaging (DTI) studies indicate that corticostriatal circuitry is similarly organized into segregated and converging loops in humans (Lehéricy et al., 2004; Leh et al., 2007; Draganski et al., 2008; Verstynen et al., 2012) and resting state functional connectivity analysis of the human striatum has shown functional organization of corticostriatal loops into affective, cognitive, and motor components (Di Martino et al., 2008; Choi et al., 2012).

ASD is characterized by abnormal functional and structural connectivity (Just et al., 2004; Cherkassky et al., 2006; Alexander et al., 2007; Keller et al., 2007; Kleinhans et al., 2008; Di Martino et al., 2010; Weng et al., 2010; Langen et al., 2011a,b; Müller et al., 2011; Sato et al., 2012; Von dem Hagen et al., 2012). Despite the growing evidence implicating frontostriatal circuitry in ASD pathology, few studies have specifically examined connectivity within this circuit. In a resting state study of corticostriatal connectivity, children with ASD showed increased connectivity between the caudate and putamen and a number of cortical and subcortical regions (Di Martino et al., 2010). Only one previous DTI tractography study has examined frontostriatal structural connectivity in ASD. The ASD group showed lower fractional anisotropy (FA) in tracts connecting the putamen to the frontal cortex, and increased mean diffusivity (MD) in tracts connecting the NAcc to the frontal cortex (Langen et al., 2011a,b).

To date, no previous study has combined functional and structural MRI data from the same participants to examine the connectivity of frontostriatal circuitry in ASD. In the present study, we investigated functional connectivity between frontostriatal regions and potential white matter differences underlying group differences in functional connectivity. Group differences in connectivity were examined in relation to behavioral impairments and striatal deactivation to social rewards as previously reported in the same particpants (Delmonte et al., 2012).

\section{METHODS \\ PARTICIPANTS}

Twenty-eight right-handed Caucasian male ASD [mean age $(S D)=17.28$ (3.57) years] and 27 right-handed male, age and IQ matched controls [mean age $(S D)=17.15$ (3.64) years] took part in the MRI study. Twenty-one ASD and control participants were retained for the fMRI analysis and 22 ASD and 24 control participants were included in the DTI analysis after excluding subjects for excessive motion (movements $>3 \mathrm{~mm}$ ) or poor data quality. ASD participants were recruited through an associated genetics research programme, clinical services, schools and advocacy groups. Controls were recruited through schools, the university and volunteer websites. Ethical approval was obtained from the St. James's Hospital/AMNCH (ref: 2010/09/07) and the Linn Dara CAMHS Ethics Committees (ref: 2010/12/07). Written informed consents/assents were obtained from all participants and their parents (where under 18 years of age).

Exclusion criteria included a Full Scale IQ (FSIQ) $<70$, known psychiatric, neurological, or genetic disorders, a history of a loss of consciousness for more than $5 \mathrm{~min}$ and those currently taking psychoactive medication. Four subjects in the ASD group had a secondary diagnosis of Attention Deficit Disorder
(ADD) or Attention Deficit Hyperactivity Disorder (ADHD). Controls were excluded if they had a first degree relative with ASD or scored above 50 on the Social Responsiveness Scale (SRS) (Constantino et al., 2003) or above 10 on the Social Communication Questionnaire (SCQ) (Rutter et al., 2003). The Adult prepublication version of the SRS was used with permission in cases 18 years or older (Constantino and Todd, 2005). All participants had normal, or corrected to normal, vision.

\section{DIAGNOSTIC ASSESSMENTS AND COGNITIVE MEASURES}

ASD diagnosis was confirmed using the Autism Diagnostic Observation Schedule (ADOS) (Lord et al., 1994) and the Autism Diagnostic Interview Revised (ADI-R; Lord et al., 2000). Clinical consensus diagnosis was established using DSM-IV-TR criteria and expert clinician (Louise Gallagher). FSIQ was measured using the four subtest version of the Wechsler Abbreviated Scale of Intelligence (WASI; Wechsler, 1999) or the Wechsler Intelligence scale for Children-Fourth Edition (WISC-IV; Wechsler, 2003). Performance IQ (PIQ) score was based on the Matrix Reasoning and Block Design subtests and Verbal IQ (VIQ) score on the Vocabulary and Similarities subtests.

\section{MRI DATA ACQUISITION}

A high-resolution 3D $T_{1}$-weighted MPRAGE image was acquired for each participant $(F O V=256 \times 256 \times 160 \mathrm{~mm}$; $T R=8.5 \mathrm{~ms}$; $T E=3.9 \mathrm{~ms}$; acquisition time $=7.3 \mathrm{~min}$; voxel size $=1 \times 1 \times$ $1 \mathrm{~mm}$ ). One hundred and fifty resting state (eyes shut) functional scans were acquired using a using a $T_{2}^{*}$ weighted gradient echo sequence to visualize changes in the BOLD signal ( $T R=2000 \mathrm{~ms}$, $T E=28 \mathrm{~ms}$; flip angle $=90^{\circ} ; F O V=240 \times 240 \mathrm{~mm}$; voxel size: $3 \times 3 \times 3.5 \mathrm{~mm}$, slice gap $0.35 \mathrm{~mm} ; 38$ slices; acquisition time $=5.06 \mathrm{~min}$ ). Diffusion weighted data were encoded along 32 independent directions, with one non-diffusion weighted image, using a single-shot echo-planar imaging (EPI) sequence with SENSE parallel imaging scheme (SENSivitiy Encoding; $T R=$ $12052 \mathrm{~ms} ; T E=55 \mathrm{~ms} ; B$-value 1000; slice thickness/gap FOV; slice number $=70$; voxel dimensions $2 \times 2 \times 2 \mathrm{~mm}$; acquisition time $8.08 \mathrm{~min}$ ).

\section{STATISTICAL ANALYSIS OF BEHAVIORAL DATA}

Behavioral data were analysed using SPSSv16. Two sample $t$-tests were used to examine group differences in age and IQ measures. Correlations were performed to examine relationships between structural and functional connectivity, between connectivity values and ADI-R scores and between connectivity values and striatal activation to social rewards. For correlations with the ADI-R, the DSM-5 model, which classifies ASD symptoms into social and communicative deficits (SCD) and restricted and repetitive behaviors (RRB), was used. The two factor model has been supported by a number of factor analytic studies (Boomsma et al., 2008; Frazier et al., 2008; Georgiades et al., 2012; Mandy et al., 2012). Item level data were classified into SCD or RRB symptom domains according to the two factor model reported by Georgiades et al. (2012) to create a quantitative score on each factor. Pearsons's and Spearman's rank-order correlations were used where appropriate. 


\section{FUNCTIONAL CONNECTIVITY ANALYSIS}

fMRI preprocessing was carried out in SPM8 (www.fil.ion.ucl.ac. uk/spm) in Matlab, 2009a (MathWorks Inc., United Kingdom). Before preprocessing, the origin was set to the anterior commisure for both $T_{1}$-weighted and EPI Images. The images were slice-time corrected, realigned to correct for motion artifacts and co-registered to the skull stripped $T_{1}$-weighted image. Normalization to standard stereotaxic space (Montreal Neurological Institute; MNI) was performed using the ICBM EPI template and the unified segmentation approach (Ashburner and Friston, 2005). The data were then re-sliced to a voxel size of $2 \times 2 \times 2 \mathrm{~mm}^{3}$. Finally, the images were smoothed using a $5 \mathrm{~mm}$ full-width-half-maximum (FWHM) Gaussian kernel to conform to assumptions of statistical inference using Gaussian Random Field Theory (Friston et al., 1995a,b). Given recent evidence that resting-state networks are particularly susceptible to head motion (Power et al., 2012; Van Dijk et al., 2012) independent samples $t$-tests were performed to ensure that groups did not differ on rotation or translation parameters [translation: mean ASD $=0.0401(S D=0.016)$, mean control $=0.0331(S D=0.0157)$ $p=0.136$; rotation: mean $\mathrm{ASD}=0.0006(S D=0.00002)$, mean control $=0.0005(S D=0.00002) p=0.122]$ and average framewise displacements (see Figure 1) were included as covariates of no interest in the analyses as findings from a recent resting-state study indicate that this yields similar results to removing highmovement time-points (scrubbing) (Fair et al., 2012; Di Martino et al., 2013; Satterthwaite et al., 2013; Yan et al., 2013).

Functional connectivity analysis was carried out using the CONN toolbox (http://www.nitrc.org/projects/conn/) (Whitfield-Gabrieli and Nieto-Castanon, 2012). Normalized bias corrected $T_{1}$ images were generated in SPM (http://www.fil.ion. ucl.ac.uk/spm/) and segmented into gray matter, white matter, and CSF. The principle eigenvariate of the BOLD time-courses

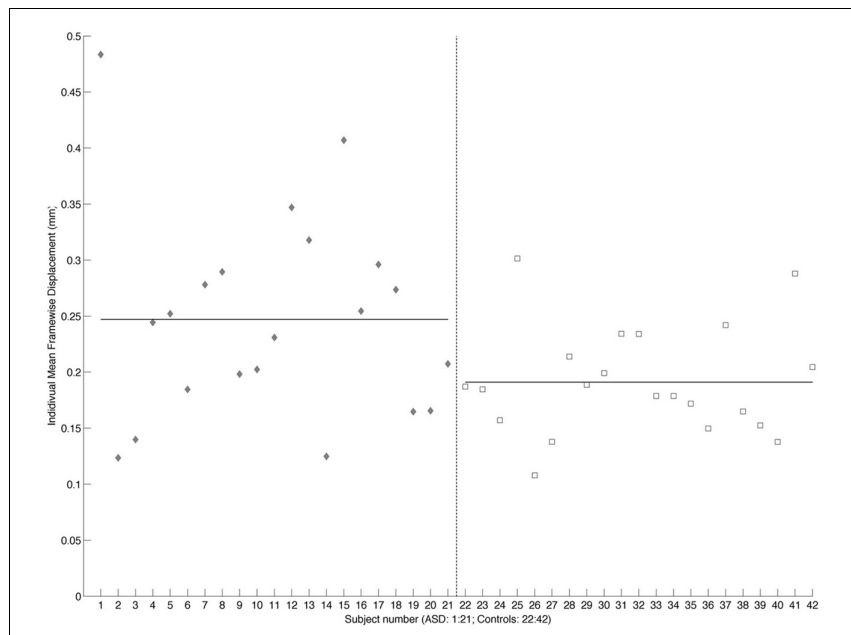

FIGURE 1 | Scatterplot showing individual mean framewise displacement. Individual subjects are shown on the $x$-axis and framewise displacement $(\mathrm{mm})$ on the $y$-axis. ASD subjects are shown as gray diamonds and controls as white squares. The dashed vertical line divides the two groups. Solid horizontal lines across the ASD and Control values show the group mean. from white matter and CSF, as well as the 6 motion correction parameters were included as regressors in the analysis to remove signals associated with these factors. The data were then band pass filtered between 0.008 and $0.2 \mathrm{~Hz}$ as recommended by Baria et al. (2011). A hanning window was used to weight down the initial and end scans within the resting state period. Seed regions were defined within the left and right frontal cortex [including the frontal medial and orbital cortices, inferior frontal gyrus, pars opercularis and pars triangularis, frontal pole, middle, superior frontal gyrus, subcallosal cortex, cingulate gyrus-anterior division, the paracingulate gyrus, precentral gyrus, and juxtapositional lobule cortex/supplementary motor area (see Figure 2)]. As the amygdala provides important inputs to the striatum (Haber, 2003; Groenewegen et al., 2003; Haber and Knutson, 2009) and has been implicated in functional and structural MRI studies of ASD (Baron-Cohen et al., 2000; Schultz, 2005; Verhoeven et al., 2009; Groen et al., 2010; Greimel et al., 2012a,b; Sato et al., 2012), it was also included as a seed region in this analysis (see Figure 3). Target regions included the left and right caudate, putamen, and NAcc (see Figure 3). Masks for these regions were generated using the Harvard-Oxford probabilistic atlas in FSL (http://fsl.fmrib.ox.ac.uk/fsl/fslwiki/) and thresholded at $20 \%$. The ROI time series were defined as the principle eigenvariate of the time series within the ROI voxels using principle component decomposition. ROI-to-ROI correlational analyses were performed between each of the seed regions in the frontal cortex and amygdala and the target regions in the striatum. Second level random effects analyses were computed to examine group differences in connectivity using a $t$-test with age, IQ, and frame-wise displacements included as covariates to control for the effects of these factors. Results were corrected for multiple comparisons for the target regions at the FDR threshold $(p<0.05)$.

\section{DIFFUSION TENSOR TRACTOGRAPHY}

Preprocessing of diffusion weighted data was carried out using Explore DTI (Leemans et al., 2009). The data were first screened by looping through each subjects' image to ensure that there were no gross artifacts such as signal dropout. Data were then corrected for eddy current distortions and subject motion with b-matrix rotation to preserve orientational information (Leemans and Jones, 2009). First, the diffusion-weighted images were realigned to the non-diffusion weighed (B0) image using a full affine transformation and cubic interpolation. Motion tensor values were estimated using robust estimation of tensors by outlier rejection (RESTORE; Chang et al., 2005). The RESTORE method improves tensor estimation compared to the linear and non-linear least squares methods, correcting for distortions due to fat suppression and cardiac pulsation. The final preprocessing step involved correcting for physically implausible signals. The data were then visually inspected to ensure that the gradient components were in the correct orientation. Finally, participants were excluded for excessive motion $(>3 \mathrm{~mm}$ ), with $22 \mathrm{ASD}$ and 24 control participants retained for further analysis.

Tractography analyses were confined to intra-hemispheric tracts between regions that showed significant group differences in functional connectivity. Whole brain tractography was carried 


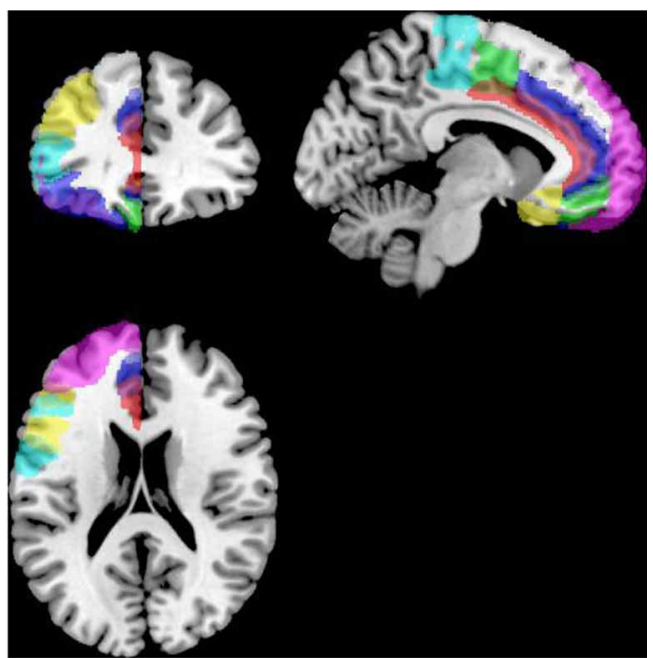

FIGURE 2 | Masks for the frontal cortex (only the left hemisphere is shown). ACC is shown in red, the OFC in blue, the MPFC in green, frontal pole in violet, IFG opercularis in yellow, IFG triangularis in cyan, juxapositional lobe in green, MFG in yellow, paracingulate in blue, precentral gyrus in light blue, SFG in grayscale and the subcallosal gyrus in yellow, displayed on the left hemisphere of a standard brain in neurological convention (left is left and right is right).

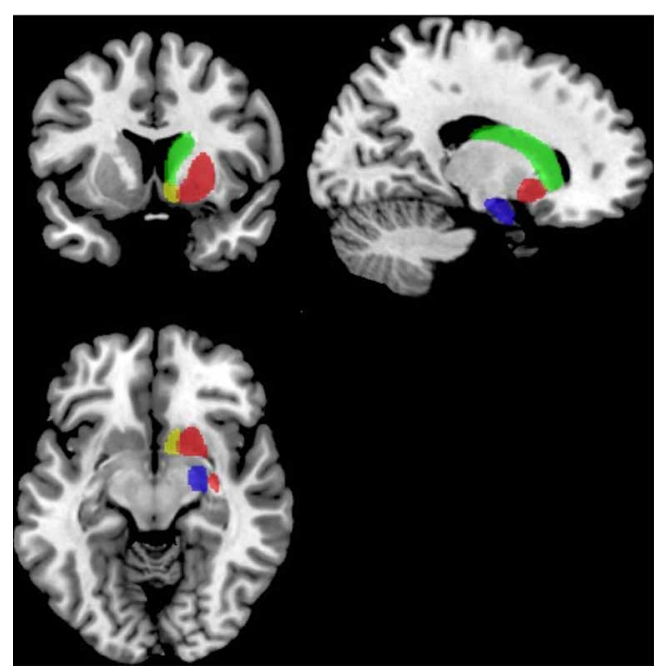

FIGURE 3 | Masks for the striatum and amygdala. The NACC is shown in yellow, the caudate in green, the putamen in red and the amydgala in blue displayed on the right hemisphere of a standard brain in neurological convention (left is left).

out using the deterministic streamline algorithm (Basser et al., 2000) as implemented in Explore DTI (Leemans et al., 2009). Tractography was carried out in each subjects' native space using a $2 \mathrm{~mm}$ seed point resolution, a $1 \mathrm{~mm}$ step size, an angle threshold of $30^{\circ}$ and an FA tract termination threshold of 0.2. Specific tracts of interest were then isolated using regions of interest (ROIs) with inclusive Boolean logical "AND" operators used to include tracts passing through a specific regions and exclusion "NOT"

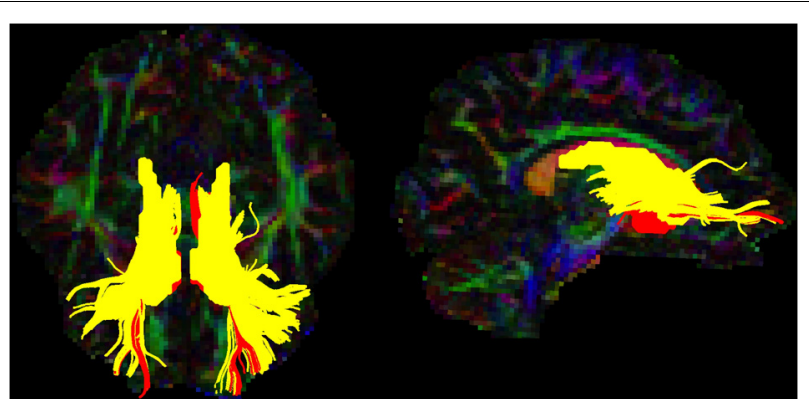

FIGURE 4 | Caudate and NAcc tracts for the template subject. Tracts are shown in the axial (left) and sagittal (right) planes in neurological convention (left is left). The caudate-prefrontal tracts are shown in yellow and NAcc-prefrontal tracts are shown in red.

operators used to exclude tracts passing through other regions. The atlas based segmentation approach was used to define ROIs in a template subject's native space (Lebel et al., 2008). These ROIs were then transformed to each subjects' native space for tractography analysis. A template subject was chosen at random as in Lebel et al. (2008). Masks of the caudate and NAcc from the Harvard-Oxford atlas, and a mask of the frontal cortex from the MNI atlas were created in FSL and thresholded at $20 \%$ in SPM8. These masks were then transformed to the template subjects native space by (i) co-registering the subjects T1 image to the subject's motion distortion corrected FA map (ii) multiplying the masks by the inverse transform parameters (MNI->Native space) generated using the segmentation option in SPM, (iii) re-slicing the masks to the same dimensions as the FA map and binarising them using the "imcalc" option in SPM. These masks were then visually inspected to ensure that they provided a good fit to the anatomical structure. Tractography analysis was carried out in the template subject using these inclusion masks (see Figure 4). "AND" gates were then placed at the caudate and NAcc to include only the regions from which tracts projected to the PFC. NOT gates were drawn in the planes across the midline and the posterior commisure, and to exclude motor tracts, cortico-spinal tracts, tracts from the corpus callosum and tracts to the temporal lobe. The atlas based segmentation tool was used to carry out tractography analysis in each subject's native space using the ROIs transformed into the subject specific space for each tract as this method has been successfully applied to improve tract delineation (Verhoeven et al., 2010). An upper limit of $100 \mathrm{~mm}$ was placed on the tract length. Outliers were excluded for each group separately for $\mathrm{FA}, \mathrm{MD}, \mathrm{RD}$ and $\mathrm{AD}$ values that were greater than 1.5 box lengths from the inter-quartile range. Multivariate analyses were computed to compare groups in terms of FA, MD, RD, and AD.

\section{RESULTS}

Groups did not differ in terms of age or IQ (see Table 1).

\section{STRIATAL FUNCTIONAL CONNECTIVITY Group-wise comparisons}

Regions showing significantly increased functional connectivity between the frontal cortex and the striatum in the ASD group 
are listed in Table 2. There were no regions that showed significantly reduced connectivity between the frontal cortex and the striatum and there were no significant group differences in connectivity between the amygdala and striatum. Bar charts showing $z$-transformed $r$-values, adjusted for age, IQ and frame-wise displacements, for connectivity between each of the regions for which there was a significant group difference can be seen in Figure 5. The ASD group showed significant positive connectivity between regions for which there were significant connectivity differences between groups, whereas controls showed negative connectivity between these regions at rest, when adjusting for age, IQ and frame-wise displacements. With the exception of right MFG to NAcc connectivity, negative connectivity was no longer apparent between frontostriatal regions in controls when covariates were not included in the analysis. Within group values for regions showing significant group differences in connectivity can be seen in Table 3 .

\section{Correlations with social reward processing}

The same participants previously completed an fMRI study of social and monetary reward processing (Delmonte et al., 2012), the results of which indicated that the ASD group showed deactivation to social rewards in the left caudate. We therefore explored whether increased connectivity between the right ACC and the

Table 1 | Mean age and 10 scores.

\begin{tabular}{llll}
\hline & Autism & Controls & $\boldsymbol{P}$ \\
\hline Age & $17.28(3.57)$ & $17.15(3.64)$ & 0.545 \\
WASI & & & \\
Full Scale IQ & $109.25(15.04)$ & $111.85(12.32)$ & 0.889 \\
Verbal IQ & $108.54(14.22)$ & $110.52(13.59)$ & 0.967 \\
Performance IQ & $107.52(14.68)$ & $110.81(11.11)$ & 0.660 \\
\hline
\end{tabular}

Standard deviations are shown in parenthesis.

Table 2 | T-scores and $\boldsymbol{p}$-values for regions showing significantly increased connectivity in the ASD group, controlling for age, 10 and frame-wise displacements.

\begin{tabular}{lllll}
\hline Source & Target & T-Value & $\boldsymbol{P}$-Unc & $\boldsymbol{P}$-FDR \\
\hline $\begin{array}{l}\text { Right cingulate gyrus, } \\
\text { anterior division }\end{array}$ & Right accumbens & 2.52 & 0.016 & 0.032 \\
& $\begin{array}{l}\text { Right caudate } \\
\text { Left caudate }\end{array}$ & 2.72 & 0.009 & 0.029 \\
& 2.98 & 0.005 & 0.029 \\
\hline Right middle frontal & Right accumbens & 2.68 & 0.011 & 0.044 \\
gyrus & Right caudate & 2.56 & 0.015 & 0.044 \\
\hline Right paracingulate & Right accumbens & 3.24 & 0.003 & 0.014 \\
gyrus & Right caudate & 3.01 & 0.005 & 0.014 \\
\hline Right frontal orbital & Right accumbens & 2.67 & 0.011 & 0.048 \\
gyrus & Left accumbens & 2.53 & 0.016 & 0.048 \\
\hline $\begin{array}{l}\text { Left paracingulate } \\
\text { gyrus }\end{array}$ & Right accumbens & 2.92 & 0.006 & 0.018 \\
& Right caudate & 3.04 & 0.004 & 0.018 \\
& Left caudate & 2.38 & 0.023 & 0.045
\end{tabular}

left caudate in ASD was associated with deactivation to social rewards. There was a negative correlation between connectivity and SID activation in ASD but not controls (ASD: $r=-0.576$, $p=0.006$; CON: $r=0.234 ; p=0.307$ ), see Figure 6. In the ASD group, deactivation to social rewards in the left caudate was associated with increased connectivity between the left caudate and the anterior cingulate.

\section{Correlations with behavior}

There was a positive correlation between connectivity in the right MFG and the right caudate and RRB in the ASD group $(r=0.573, p=0.008)$; greater connectivity was associated with greater impairment. Connectivity between the right and left Pcg and the right NAcc was negatively correlated with SCD in the ASD group $(r=-0.511, p=0.012 ; r=-0.572 ; p=$ 0.008 ); greater connectivity was associated with less impairment. Similarly, there was a negative correlation between connectivity between the right OFC and right NAcc and SCD score in the ASD group $(r=-0.519 ; p=0.019)$. Associations between connectivity values and behavioral measures can be seen in Figure 7. These correlations did not withstand correction for multiple comparisons at the bonferroni level $\left[p_{(0.05 / 24)}=0.002\right]$. Twentyfour correlations were performed as there were twelve regions showing significant group differences in functional connectivity and 2 behavioral measures. Figure 7 shows plots of the correlations between connectivity values and behavioral measures in the ASD group.

\section{STRIATAL STRUCTURAL CONNECTIVITY}

Multivariate analyses with age, I.Q. and TIV entered as covariates indicated that there were no significant between group differences in $\mathrm{FA}, \mathrm{MD}, \mathrm{RD}$, or $\mathrm{AD}$ in the tracts of interest.

\section{CORRELATIONS BETWEEN STRUCTURAL AND FUNCTIONAL CONNECTIVITY}

There was a significant positive correlation between $\mathrm{AD}$ in the right caudate to prefrontal tract and functional connectivity (raw $\mathrm{z}$-scores) between the right MFG and the right caudate across the group as a whole $(r=0.414, p=0.010)$, however, a within group analysis showed only a trend in the ASD group $(r=0.445$, $p=0.056)$ and no relationship with control participants $(r=$ $0.214, p=0.380$ ) indicating that the significant correlation was largely driven by variance in the ASD group. There were no other significant correlations between functional and structural connectivity.

\section{DISCUSSION}

The ASD group showed increased functional connectivity between the ACC, Pcg, OFC, and the MFG in the prefrontal cortex and the caudate and NAcc in the striatum, with group differences primarily in the right hemisphere. Increased functional connectivity between frontostriatal regions in ASD was associated BOLD deactivation to social rewards (Delmonte et al., 2012) and behavioral measures of SCD and RRB. There were no significant group differences in the structure of frontostriatal tracts. This suggests that group differences in functional connectivity, reported in the present study, may not be due to alterations in 


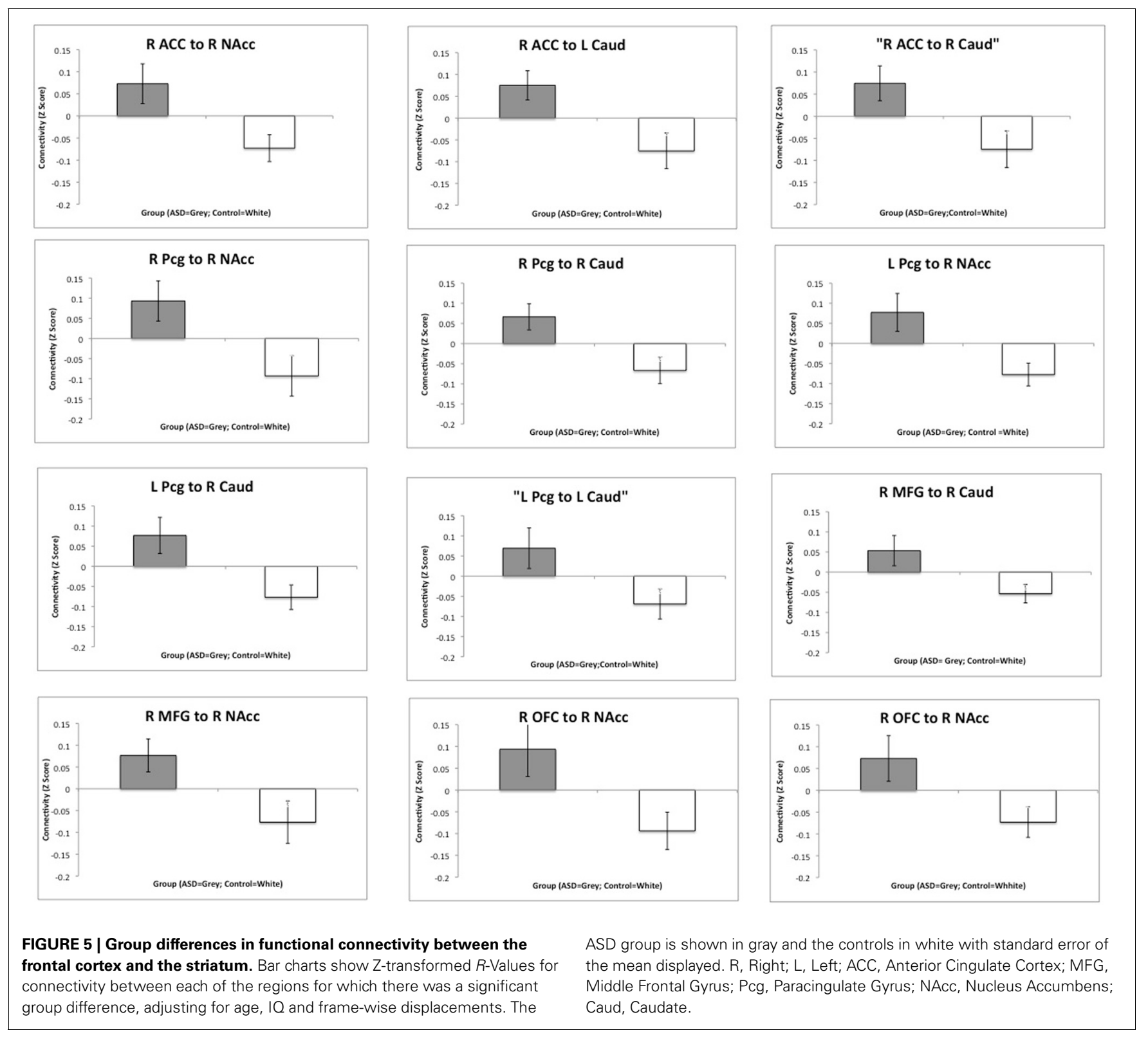

frontostriatal structural connectivity in ASD, though these findings could also reflect methodological issues associated with DTI tractography.

\section{GROUP DIFFERENCES IN FUNCTIONAL CONNECTIVITY Hyperconnectivity between the anterior cingulate cortex (ACC) and striatum in ASD}

Neuranatomical connections between the ACC and the striatum are organized in functionally distinct loops. The ventral ACC is connected to the ventral and dorsal striatum (VS and DS) and the dorsal ACC to the DS (Beckmann et al., 2009). ACC regions connected to the VS are involved in emotion, reward and pain whereas regions connected to the DS are mostly involved in motor functions, conflict/error detection and reward (Beckmann et al.,
2009). The dorsal cognitive division of the ACC is connected to other regions involved in attention including the dorsolateral prefrontal cortex (dlPFC) and parietal attention regions. The rostral-ventral affective division is connected to limbic regions including the OFC, amygdala, and periaqueductal gray (PAG) (Bush et al., 2000).

Previous findings, together with the present results, suggest that hyperconnectivity between the ACC and caudate may be specific to adolescents/adults with ASD. Increased bilateral connectivity between the ACC and caudate has been reported during visuomotor performance among adults with ASD (Turner et al., 2006) but not resting state among children with ASD (Di Martino et al., 2010). ACC pathology has also been implicated more generally in functional and structural neuroimaging studies of ASD. 


\begin{tabular}{|c|c|c|c|}
\hline Source & Target & $T$-value & P-FDR \\
\hline $\begin{array}{l}\text { Right cingulate } \\
\text { gyrus, anterior } \\
\text { division }\end{array}$ & $\begin{array}{l}\text { Right accumbens } \\
\text { Left caudate } \\
\text { Right caudate }\end{array}$ & $\begin{array}{l}\text { ASD }=2.53 \\
\text { Control }=-2.35 \\
A S D=2.98 \\
\text { Control }=-2.76 \\
A S D=2.67 \\
\text { Control }=-2.36\end{array}$ & $\begin{array}{l}\text { ASD }=0.0314 \\
\text { Control }=-0.0486 \\
A S D=0.0299 \\
\text { Control }=0.0486 \\
\text { ASD }=0.0314 \\
\text { Control }=0.049\end{array}$ \\
\hline $\begin{array}{l}\text { Right middle } \\
\text { frontal gyrus }\end{array}$ & $\begin{array}{l}\text { Right accumbens } \\
\text { Right caudate }\end{array}$ & $\begin{array}{l}\text { ASD }=2.73 \\
\text { Control }=-2.68 \\
\text { ASD }=2.62 \\
\text { Control }=-2.64\end{array}$ & $\begin{array}{l}\text { ASD }=0.0378 \\
\text { Control }=0.0355 \\
\text { ASD }=0.0378 \\
\text { Control }=0.0355\end{array}$ \\
\hline $\begin{array}{l}\text { Right } \\
\text { paracingulate } \\
\text { gyrus }\end{array}$ & $\begin{array}{l}\text { Right accumbens } \\
\text { Right caudate }\end{array}$ & $\begin{array}{l}\text { ASD }=3.29 \\
\text { Control }=-3.55 \\
\text { ASD }=3.07 \\
\text { Control }=-3.14\end{array}$ & $\begin{array}{l}\text { ASD }=0.0118 \\
\text { Control }=0.0006 \\
\text { ASD }=0.0118 \\
\text { Control }=0.0009\end{array}$ \\
\hline $\begin{array}{l}\text { Right frontal } \\
\text { orbital gyrus }\end{array}$ & $\begin{array}{l}\text { Right accumbens } \\
\text { Left accumbens }\end{array}$ & $\begin{array}{l}\text { ASD }=2.67 \\
\text { Control }=-2.47 \\
\text { ASD }=2.38 \\
\text { Control }=-1.91\end{array}$ & $\begin{array}{l}\text { ASD }=0.0484 \\
\text { Control }=0.07 \\
\text { ASD }=0.0484 \\
\text { Control }=0.09\end{array}$ \\
\hline $\begin{array}{l}\text { Left } \\
\text { paracingulate } \\
\text { gyrus }\end{array}$ & $\begin{array}{l}\text { Right accumbens } \\
\text { Right caudate } \\
\text { Left caudate }\end{array}$ & $\begin{array}{l}\text { ASD }=2.98 \\
\text { Control }=-3.05 \\
A S D=0.3 .00 \\
\text { Control }=-2.68 \\
A S D=2.39 \\
\text { Control }=-2.25\end{array}$ & $\begin{array}{l}\text { ASD }=0.0149 \\
\text { Control }=0.0247 \\
A S D=0.0149 \\
\text { Control }=0.0328 \\
A S D=0.0436 \\
\text { Control }=0.06\end{array}$ \\
\hline
\end{tabular}

In a meta-analysis of functional neuroimaging studies, hypoactivation was reported in the perigenual ACC in ASD during social tasks and in the dorsal ACC for non-social tasks (Di Martino et al., 2009). Reduced ACC gray matter volume (Haznedar et al., 2000; Greimel et al., 2012a,b) and surface area (Hadjikhani et al., 2006; Doyle-Thomas et al., 2012), primarily in the right hemisphere, have also been reported.

Hyperconnectivity between the right ACC and the left caudate was associated with deactivation to social rewards in ASD as reported in a previous study among the same participants (Delmonte et al., 2012). This is in keeping with the role of the ACC in social perception and social cognition deficits in ASD (Di Martino et al., 2009) and with recent evidence of abnormal ACC activation during social and non-social reward processing (Dichter et al., 2011; Kohls et al., 2012a,b)—although we did not observe the latter in our previous study. Taken together these results suggest that abnormal activation in the left caudate during social reward feedback may have been due to abnormal top-down processes governed by the ACC.

\section{Hyperconnectivity between the paracingulate (Pcg) and striatum in ASD}

The Pcg is often thought of as part of the ACC (Gallagher and Frith, 2003; Walter et al., 2005), though it is anatomically,

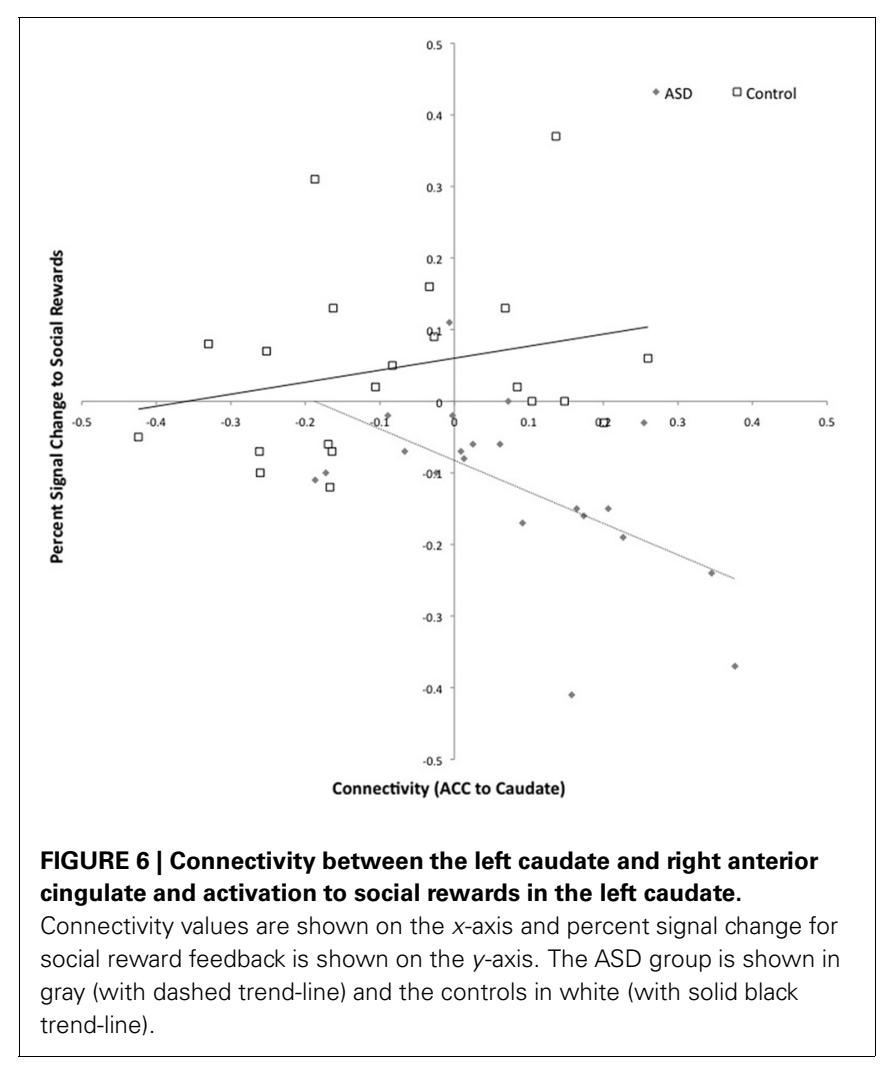

and perhaps functionally, distinct from the ACC (Gallagher and Frith, 2003). Diffusion MRI data in humans indicates that it is connected to the VS and DS and the dorsal prefrontal cortex (Beckmann et al., 2009). The Pcg is involved in emotion, social interaction, reward and decision-making, conflict monitoring and error detection (Vogt, 2005; Amodio and Frith, 2006; Beckmann et al., 2009). The anterior Pcg, along with the superior temporal sulci and the temporal poles, plays an important role in theory of mind (Gallagher and Frith, 2003; Walter et al., 2005) with activation modulated by the amount of social interaction involved in the task (Walter et al., 2004). The Pcg and striatum are thought to be involved in separate phases of decision-making, with the Pcg involved in action selection and the VS responding to positive outcomes (Rogers et al., 2004).

Previous functional connectivity studies of the striatum in ASD have not implicated the Pcg (Turner et al., 2006; Di Martino et al., 2010), however, reduced connectivity between the Pcg and the intraparietal sulcus during working memory task performance (Koshino et al., 2005) and reduced connectivity with the IFG during sentence comprehension have been reported in ASD (Just et al., 2004). Additionally, reduced Pcg activation during theory of mind tasks (Kana et al., 2009) and reduced gray matter volume in the right Pcg (Abell et al., 1999) have been reported. In the present study increased connectivity between the Pcg and the NAcc was negatively associated with SCD deficits, suggesting that increased connectivity between these regions in people with high functioning ASD could reflect a compensatory mechanism. 

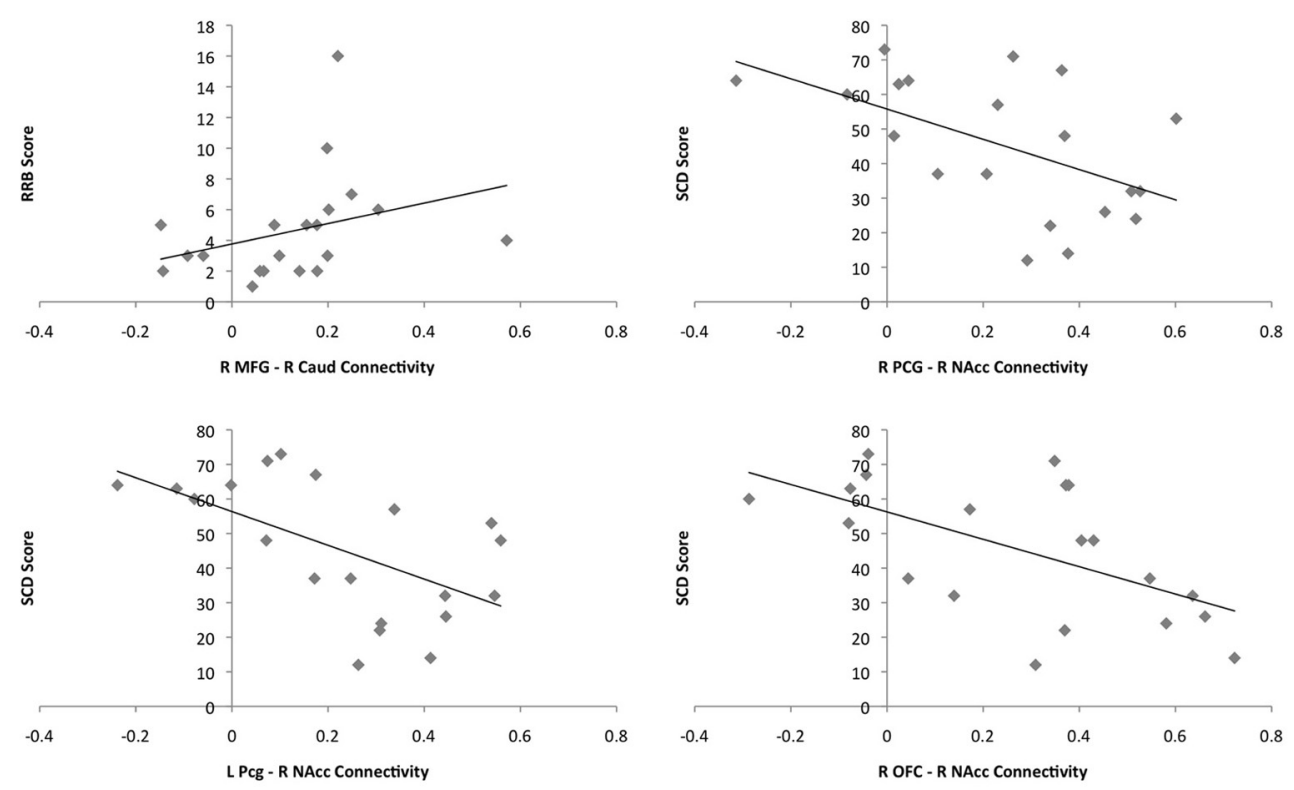

FIGURE 7 | Plots of the correlations between connectivity values and behavioral measures for the ASD group. Connectivity values are shown on the $x$-axes and scores on the behavioral measures on the $y$-axes. ASD single subjects are represented as gray diamonds (solid black trend-line).

\section{Hyperconnectivity between the middle frontal gyrus (MFG) and striatum in ASD}

The MFG, along with part of the SFG, comprises the dlPFC (Barbas and Pandya, 1989; Badre and D'Esposito, 2009; Yeterian et al., 2012), which is connected to the rostral dorsolateral caudate as well as the OFC and medial prefrontal cortex (mPFC) (Haber, 2003; Lehéricy et al., 2004; Leh et al., 2007; Draganski et al., 2008). The dlPFC is involved in a host of executive functions including working memory, set-shifting, rule learning, and planning (Goldman-Rakic et al., 1996; Leung et al., 2002; Badre and D'Esposito, 2009) and is thought to work together with the caudate to mediate these functions (Haber, 2003; Pasupathy and Miller, 2005). In terms of rule-learning, rewarded associations are thought to be identified in the striatum, which trains slower learning mechanisms in the dlPFC (Pasupathy and Miller, 2005). The dlPFC is involved in rule-learning via reinforcement; once the rule has been acquired, the dlPFC is no longer required and action execution is controlled by the premotor cortex (Badre and D'Esposito, 2009).

As in previous studies of striatal connectivity (Turner et al., 2006; Di Martino et al., 2010), there was a significant increase in connectivity between the caudate and MFG in ASD. In addition, the ASD group showed hyperconnectivity between the MFG and the NAcc. This is in keeping with a body of evidence implicating the MFG/dlPFC in ASD. Decreased functional connectivity has been reported between the dIPFC and the visuospatial regions in the occipital and parietal lobes during visuospatial processing (Damarla et al., 2010). ASD subjects also show less negative correlation between the dIPFC and amygdala during passive viewing of emotional facial expressions (Rudie et al., 2011) and increased regional homogeneity (local synchronization of the BOLD signal) in the right MFG during rest (Paakki et al., 2010). Reduced activation in the dlPFC during social and non-social information processing, including spatial working memory (Luna et al., 2002), sustained attention (Christakou et al., 2012) and memory encoding of social information have been recorded (Greimel et al., 2012a,b) as well as abnormal involvement in tasks such as gaze perception (Vaidya et al., 2011). In addition, increased gray matter volume (Ecker et al., 2012) and neuronal number (Courchesne et al., 2011) indicate structural abnormalities in the dlPFC in ASD.

Connectivity between the right MFG and right caudate was associated with increased RRB. This in keeping with previous literature implicating the frontostriatal circuitry, particularly the caudate and MFG/dlPFC, in executive function and repetitive behavior deficits in ASD (Hollander et al., 2005; Rojas et al., 2006; Estes et al., 2011; Langen et al., 2011a; Ecker et al., 2012) and suggests that cognitive as opposed to sensorimotor circuitry is implicated in repetitive behaviors in high functioning ASD.

\section{Hyperconnectivity between the orbitofrontal cortex (OFC) and striatum in ASD}

The OFC is involved emotion, motivation and reward, and is the region of prefrontal cortex most often associated with rewardguided decision-making, subserving both sensory and abstract reward processing (Haber, 2003; Haber and Knutson, 2009; Rushworth et al., 2011). Specifically, OFC activity is thought to reflect signal valuation, for both rewards and punishments, tracking expected reward value prior to decision-making and the received reward value after a choice has been made (Rushworth et al., 2011). Efferent connections from the OFC provide input to 
the VS, with the VS also receiving input from the amygdala and hypothalamus (Haber, 2003; Draganski et al., 2008). The OFC, together with the VS and amygdala, is thought to compute the salience value of social stimuli, with this circuitry playing a potential role in social motivation deficits in ASD (Chevallier et al., 2012; Kohls et al., 2012a,b).

Previous fMRI studies have indicated abnormal activation of the OFC, VS and amygdala during both social and non-social reward processing in ASD (Scott-Van Zeeland et al., 2010; Dichter et al., 2011, 2012; Kohls et al., 2012a,b), providing support for the hypothesized role of these regions in social motivation difficulties in ASD. Additionally, structural alterations have been recorded in the OFC in ASD, including decreased gray matter volume (Ecker et al., 2012), increased cortical thickness (Hyde et al., 2010) and altered sulcogyral morphology (Watanabe et al., 2013). Previous examinations of frontostriatal functional connectivity in ASD have not specifically implicated abnormal OFC_-VS connectivity (Turner et al., 2006; Di Martino et al., 2010). The results of the present study indicated that increased connectivity between the OFC and NAcc was associated with fewer SCD deficits, suggesting that increased connectivity between these regions may function to reduce social difficulties among adolescents/young adults with high-functioning ASD.

\section{FRONTOSTRIATAL STRUCTURAL CONNECTIVITY}

There were no significant group differences in white matter microstructure (FA, MD, RD, $\mathrm{AD}$ ) in tracts connecting the caudate or NAcc to the prefrontal cortex. Only one previous study has specifically examined microstructural integrity of frontostriatal circuits. Greater MD was reported in projections between the right NAcc and prefrontal cortex but not in projections between the caudate and prefrontal cortex among adults with ASD (Langen et al., 2011a,b). The disparity between the present findings and those of Langen et al. (2011a,b) could be due to age differences between the samples, with the sample in the present study being younger than those previously examined. The difference between structural and functional connectivity findings in the present study, with significant group differences for functional data but not structural data, may be due to several factors. Resting state connectivity analysis is not anatomically constrained therefore differences in connections between the striatum and PFC could potentially arise from structural alterations in another part of the circuit, for example in fiber pathways connecting the striatum and pallidum, pallidum and thalamus, or thalamus and cortex. Frontostriatal connections may be characterized by topographical reorganization of fiber pathways in ASD rather than microstructural alterations. This could be explored using connectivity based classification methods (Behrens et al., 2007). Another potential explanation is that structural data may be less sensitive to group differences than functional data (Finger et al., 2012) or that subtle white matter differences may remain undetected by the typical "tract averaged" approach used in most tractography studies and may require the use of "tract resampling" techniques to capture more subtle variations over the length of a tract (Colby et al., 2012). Finally, with the exception of a significant correlation between functional connectivity between the right caudate and $\mathrm{MFG}$, and $\mathrm{AD}$ in the right caudate to prefrontal tract, measures of functional connectivity were unrelated to structural metrics in the present study. Greater concordance between functional and structural connectivity metrics may be obtained by examining specific loops (i.e., cingulo-striatal loops or dlPFCstriatal loops) in frontostriatal circuitry rather than connections between the striatum and the entire frontal cortex. It is likely that such analyses would require high-resolution diffusion imaging (HARDI) data and advanced modeling techniques such as constrained spherical deconvolution (CSD) rather than the tensor model used here.

\section{LIMITATIONS AND FUTURE DIRECTIONS}

The results of the present study should be interpreted in the light of several methodological issues. We did not replicate previous findings showing positive functional connectivity between frontostriatal regions, for example between the MFG and the caudate, in our control group (Di Martino et al., 2008). This is perhaps due to developmental factors related to the age range of the participants in the present study. Indeed negative connectivity between frontostriatal regions in controls was no longer apparent when covariates were not included in the analyses. Another potential explanation is that Di Martino et al. (2008) divided the caudate into ventral and dorsal regions, which showed distinct patterns of connectivity with sub-regions of the ACC and dlPFC, whereas we examined connectivity using gross morphological boundaries. Examining connectivity across entire structures in the current study may have obscured functional relationships between sub-regions of these structures. This can be circumvented to some extent by using a seed-to-voxel approach rather than the ROI-to-ROI approach taken in this study. However, the seed-to-voxel approach also requires a significantly greater number of statistical comparisons, which can potentially lead to Type II errors (false negatives). Given that ASD is a functionally heterogeneous population and this study has a relatively small sample size $(N=21)$, the ROI-to-ROI approach used in the present study is likely to have been more sensitive to group differences. Recent studies have shed light on the topography of functional and structural connections within the striatum (Robinson et al., 2012; Verstynen et al., 2012; Tziortzi et al., 2013) which may be useful in defining seed regions for future studies of functional and anatomical connections in frontostriatal circuitry in ASD.

A limitation of functional connectivity methods used in the present study is that one cannot infer the source of differences in functional connectivity. Frontostriatal loops are part of larger circuitry which also involve thalamo-cortical connections (Haber and Knutson, 2009). Increased connectivity between the thalamus and frontal cortical regions has been reported in ASD (Mizuno et al., 2006), indicating that thalamo-cortical circuitry is also abnormal in ASD, which could impact on frontostriatal circuitry. Given the looped structure of cortico-striatal-thalamo-cortical connections (Alexander et al., 1986, 1990), and various regulatory influences on this circuitry (Haber and Knutson, 2009), it is difficult to infer at what point dysregulation occurs, i.e., in the frontal cortex, the thalamus, the striatum, other regulatory subcortical structures, or in specific connections between these structures. We did not examine the connectivity of the midbrain-which 
provides important dopaminergic input to the striatum (Schultz et al., 1997; Haber and Knutson, 2009)—due to the fact that the midbrain is particularly susceptible to artifacts from cardiac (Greitz et al., 1992; Dagli et al., 1999) and respiratory (Raj et al., 2001) signals. Future studies could examine midbrain function in ASD using optimized fMRI methods (LimbrickOldfield et al., 2012), could include additional ROIs in regions such as the midbrain and thalamus, and could use effective connectivity modeling techniques to more fully characterize connectivity within frontostriatal circuitry (and potentially shed light on the source of hyperconnectivity in this circuit) in ASD.

The lack of group differences in structural connectivity should be interpreted in the light of several factors. Firstly, DTI is associated with a number of confounds (Jones, 2010). The tensor model cannot characterize diffusion in regions of complex fiber architecture, or "crossing fibers" where fibers kiss, twist, splay kink, or bend (Basser et al., 2000; Frank, 2001; Tuch, 2004; Jones, 2010). This is an important issue given that crossing fibers are thought to make up to $90 \%$ of white matter (Jeurissen et al., 2012). Tensor derived metrics are also influenced by acquisition parameters, such as the $b$-value (Vos et al., 2012), which may further confound results. Improved understanding of brain structural connectivity in ASD will therefore require the use of HARDI methods such as CSD tractography. Another potential concern is that the presence of subtle differences along white matter fiber tract may remain undetected as the diffusion metrics are typically averaged along the entire tract segment under investiagtion, thus masking subtle and highly localized regions of effect. Emerging tractography techniques that assess variations in the diffuison meteric along the tract using a "tract resampling mechanism" have been shown to potentially increase the sensitivity of analyses to the presence of very subtle but important white matter fiber differences (Colby et al., 2012). Again the use of HARDI methods may provide futher insight into more subtle stuctural differences in ASD. Another potential methodological issue is that the age range of the participants in the present study may have introduced heterogeneity in the data due to ongoing developmental processes, which could have reduced power to detect group differences. Previous studies suggest that both gray and white matter undergo different developmental trajectories in ASD (Carper et al., 2002; Keller et al., 2007; Langen et al., 2009; Cheng et al., 2010; Mak-Fan et al., 2012), therefore future studies should use tighter age ranges to limit heterogeneity for group-wise comparisons. Finally, the size of the sample in the

\section{REFERENCES}

Abell, F., Krams, M., Ashburner, J., Passingham, R., Friston, K., Frackowiak, R., et al. (1999). The neuroanatomy of autism: a voxel-based whole brain analysis of structural scans. Neuroreport 10, 1647-1651. doi: 10.1097/00001756199906030-00005

Alexander, A., Lee, J. E., Lazar, M., Boudos, R., DuBray, M. B., Oakes, T. R., et al. (2007). Diffusion

present study may have reduced power to detect potential group differences in structural connectivity.

Interestingly, hyperconnectivity between the PFC and the striatum was primarily lateralized to the right hemisphere in the present study. This is in keeping with evidence that differences in the structure and function of the ACC are largely lateralized to the right hemisphere (Haznedar et al., 2000; Bejjani et al., 2012; Dichter et al., 2012; Joshi et al., 2012), that increased gray and white matter volume asymmetries are lateralized to the right hemisphere (Herbert et al., 2005) and that regional homoegeneity, a measure of functional connectivity thought to index local synchrony in the BOLD signal, is primarily lateralized to the right hemisphere in ASD (Liu et al., 2008; Paakki et al., 2010). Future studies may wish to further examine potential hemispheric asymmetries in functional and structural connectivity in ASD.

\section{CONCLUSIONS}

These results are in line with previous reports of increased functional connectivity between the striatum and frontal, temporal and parietal lobes as well as the pons in ASD (Turner et al., 2006; Di Martino et al., 2010). In the present study, hyperconnectivity was confined to limbic and associative frontostriatal circuits. Unlike previous studies (Di Martino et al., 2010), there were no group differences in sensorimotor loops. These findings add to a growing body of literature indicating significant increases as well as decreases in functional connectivity in ASD and do not support general under-connectivity accounts (Just et al., 2007), but suggest that ASD is characterized by complex functional re-organization which also involves hyperconnectivity within certain circuits. Increased functional connectivity in frontostriatal circuitry was associated with behavioral characteristics of ASD in terms of social interaction and communication and restricted interests/repetitive behaviors, as well as deactivation to social rewards in the striatum. There were no differences in structural connectivity as measured by DTI. This suggests that differences in functional connectivity were not detectable by DTI tractography in frontostriatal white matter but further research using advanced CSD based tractography is needed to clarify if subtle structural abnormalities exist in this region.

\section{ACKNOWLEDGMENTS}

We would like to thank all of the participants and their families who kindly took part in this study.

Alexander, E. G., DeLong, M. R., and Strick, P. L. (1986). Parallel organization of functionally segregated circuits linking basal ganglia and cortex. Annu. Rev. Neurosci. 9, 357-381. doi: 10.1146/annurev.ne. 09.030186.002041

Amodio, D. M., and Frith, C. D. (2006) Meeting of minds: the medial frontal cortex and social cognition. Nat. Rev. Neurosci. 7, 268-277. doi: 10.1038/nrn1884
Ashburner, J., and Friston, K. J. (2005). Unified Segmentation. Neuroimage 26, 839-851. doi: 10.1016/j.neuroimage.2005.02.018

Badre, D., and D'Esposito, M. (2009). Is the rostro-caudal axis of the frontal lobe hierarchical? Nat. Rev. Neurosci. 10, 659-669.

Barbas, H., and Pandya, D. N. (1989). Architecture and intrinsic connections of the prefrontal cortex in the rhesus monkey. 
J. Comp. Neurol. 286, 353-375. doi: $10.1002 /$ cne.902860306

Baria, A. T., Baliki, M. N., Parrish, T., and Apkarian, A. V. (2011). Anatomical and functional assemblies of brain BOLD oscillations. J. Neurosci. 31, 7910-7919. doi: 10.1523/JNEUROSCI.1296-11.2011

Baron-Cohen, S., Ring, H. A., Bullmore, E. T., Wheelwright, S., Ashwin, C., and Williams, S. C. R. (2000). The amygdala theory of autism. Neurosci. Biobehav. Rev. 24, 355-364. doi: 10.1016/S0149-7634(00)00011-7

Basser, J. P., Pajevic, S., Pierpaoli, C., Duda, J., and Aldroubi, A. (2000). In vivo fiber tractography using DTMRI data. Magn. Reson. Med. 44, 625-632.

Beckmann, M., Johansen-Berg, H., and Rushworth, M. F. S. (2009). Connectivity-based parcellation of human cingulate cortex and its relation to functional specialization. J. Neurosci. 29, 1175-1190. doi: 10.1523/JNEUROSCI.3328-08.2009

Behrens, J. T. E., Berg, J. H., Jbabdi, S., Rushworth, M. F. S., and Woolrich, M. W. (2007). Probabilistic diffusion tractography with multiple fibre orientations: what can we gain? Neuroimage 34, 144-155.

Bejjani, A., O’Neill, J., Kim, J. A., Frew, A. J., Yee, V. W., Ly, R., et al. (2012). Elevated glutamatergic compounds in pregenual anterior cingulate in pediatric autism spectrum disorder demonstrated by $1 \mathrm{H}$ MRS and $1 \mathrm{H}$ MRSI. PLOS ONE 7:e38786. doi: 10.1371/journal.pone.0038786

Boomsma, A., Van Lang, N. D. J., De Jonge, M. V., De Bildt, A. A., Van Engeland, H., and Minderaa, R. B. (2008). A new symptom model for autism cross-validated in an independent sample. J. Child Psychol. Psychiatry 49, 809-816. doi: 10.1111/j.1469-7610.2008.01897.x

Bush, G., Luu, P., and Posner, M. I. (2000). Cognitive and emotional influences in anterior cingulate cortex. Trends Cogn. Sci. 4, 215-222. doi: $\quad 10.1016 /$ S1364-6613(00) 01483-2

Carper, R. A., Moses, P., Tigue, Z. D., and Courchesnes, E. (2002). Cerebral lobes in autism: early hyperplasia and abnormal age effects. Neuroimage 16, 1038-1051. doi: 10.1006/nimg.2002.1099

Chang, L.-C., Jones, D. K., and Pierpaoli, C. (2005). RESTORE: robust estimation of tensors by outlier rejection. Magn. Reson. Med. 53, 1088-1095. doi: 10.1002/mrm.20426

Cheng, Y., Chou, K.-H., Chen, I.Y., Fan, Y.-T., Decety, J., and
Lin, C.-P. (2010). Atypical development of white matter microstructure in adolescents with autism spectrum disorders. Neuroimage 50, 873-882. doi: 10.1016/j.neuroimage.2010.01.011

Cherkassky, V. L., Kana, R. K., Keller, T. A., and Just, M. A. (2006). Functional connectivity in a baseline resting-state network in autism. Neuroreport 17, 1687-1690. doi: $\quad 10.1097 / 01 . w n r .0000239956$. $45448.4 \mathrm{c}$

Chevallier, C., Kohls, G., Troiani, V., Brodkin, E. S., and Schultz, R. T. (2012). The social motivation theory of autism. Trends Cogn. Sci. 16, 231-239. doi: 10.1016/j.tics.2012.02.007

Choi, E. Y., Yeo, B. T. T., and Buckner, R. L. (2012). The organization of the human striatum estimated by intrinsic functional connectivity. J. Neurophysiol. 108, 2242-2263. doi: 10.1152/jn.00270.2012

Christakou, A., Murphy, C. M., Chantiluke, K., Cubillo, A. I., Smith, A. B., Giampietro, V., et al. (2012). Disorder-specific functional abnormalities during sustained attention in youth with attention deficit hyperactivity disorder (ADHD) and with autism. Mol. Psychiatry 18, 236-244. doi: 10.1038/mp.2011.185

Colby, J. B., Soderberg, L., Lebel, C., Dinov, I. D., Thompson, P. M., and Sowell, E. R. (2012). Along-tract statistics allow for enhanced tractography analysis. Neuroimage 59, 3227-3242. doi: 10.1016/j.neuroimage.2011.11.004

Constantino, J. N., Davis, S. A., Todd, R. D., Schindler, M. K., Gross, M. M., Brophy, S. L., et al. (2003). Validation of a brief quantitative measure of autistic traits: comparison of the social responsiveness scale with the autism diagnostic interview-revised. J. Autism Dev. Disord. 33, 427-433. doi: 10.1023/A:1025014929212

Constantino, J. N., and Todd, R. D. (2005). Intergenerational transmission of subthreshold autistic traits in the general population. Biol. Psychiatry 57, 655-660. doi 10.1016/j.biopsych.2004.12.014

Courchesne, E., Mouton, P. R., Calhoun, M. E., Semendeferi, K., Ahrens-Barbeau, C., Hallet, M. J., et al. (2011). Neuron number and size in prefrontal cortex of children with autism. JAMA 306, 2001-2010. doi: 10.1001/jama.2011.1638

Dagli, M. S., Ingeholm, J. E., and Haxby, J. V. (1999). Localization of cardiac-induced signal change in fMRI. Neuroimage 9, 407-415. doi: 10.1006/nimg.1998.0424
Damarla, S. R., Keller, T. A., Kana, R. K., Cherkassky, V. L., Williams, D. L., Minshew, N. J., et al. (2010) Cortical underconnectivity coupled with preserved visuospatial cognition in autism: evidence from an fMRI study of an embedded figures task. Autism Res. 3, 273-279. doi: 10.1002/aur.153

Dawson, G., Bernier, R., and Ring, R. H. (2012). Social attention: a possible early indicator of efficacy in autism clinical trials. J. Neurodev. Disord. 4,11 .

Dawson, G., Webb, S. J., and McPartland, J. (2005). Understanding the nature of face processing impairment in autism: insights from behavioral and electrophysiological studies. Dev. Neuropsychol. 27, 403-424. doi: $10.1207 / \mathrm{s} 15326942 \mathrm{dn} 27036$

Delmonte, S., Balsters, J. H., McGrath, J., Fitzgerald, J., Brennan, S., Fagan, A. J., et al. (2012). Social and monetary reward processing in autism spectrum disorders. Mol. Autism 3,7 .

Dichter, S., Felder, J. N., Green, S. R., Rittenberg, A. M., Sasson, N. J., and Bodfish, J. W. (2012). Reward circuitry function in autism spectrum disorders. Soc. Cogn. Affect. Neurosci. 7, 160-172. doi: 10.1093/ scan/nsq095

Dichter, S., Richey, J. A., Rittenberg, A. M., Sabatino, A., and Bodfish, J. W (2011). Reward circuitry function in autism during face anticipation and outcomes. J. Autism Dev. Disord. 42, 147-160. doi: 10.1007/s10803-0111221-1

Di Martino, A., Kelly, C., Grzadzinski, R., Zuo, X.-N., Mennes, M., Angeles Mairena, M., et al. (2010). Aberrant striatal functional connectivity in children with autism. Biol. Psychiatry 69, 847-857. doi: 10.1016/j.biopsych. 2010.10.029

Di Martino, A., Scheres, A., Margulies, D. S., Kelly, A. M. C., Uddin, L. Q., Shehzad, Z., et al. (2008). Functional connectivity of human striatum: a resting state fMRI study. Cereb. Cortex 18, 2735-2747. doi: 10.1093/cercor/bhn041

Di Martino, A., Yan, C.-G., Li, Q. Denio, E., Castellanos, F. X., Alaerts, K., et al. (2013). The autism brain imaging data exchange: towards large-scale evaluation of the intrinsic brain architecture in autism. Mol. Psychiatry. doi: $10.1038 / \mathrm{mp}$. 2013.78. [Epub ahead of print].

Di Martino, A., Ross, K., Uddin, L. Q., Sklar, A. B., Castellanos, F. X., and Milham, M. P. (2009). Functional brain correlates of social and nonsocial processes in autism spectrum disorders: an activation likelihood estimation meta-analysis. Biol. Psychiatry 65, 63-74. doi: 10.1016/j.biopsych. 2008.09.022

Doyle-Thomas, K. A. R., Kushki, A., Duerden, E. G., Taylor, M. J., Lerch, J. P., Soorya, L. V., et al. (2012). The effect of diagnosis, age, and symptom severity on cortical surface area in the cingulate cortex and insula in autism spectrum disorders. J. Child Neurol. 28, 729-736. doi: 10.1177/ 0883073812451496

Draganski, B., Kherif, F., Klöppel, S., Cook, P. A., Alexander, D. C., Parker, G. J. M., et al. (2008). Evidence for segregated and integrative connectivity patterns in the human basal ganglia. J. Neurosci. 28, 7143-7152. doi: 10.1523/JNEUROSCI.1486-08.2008

Ecker, C., Suckling, J., Deoni, S. C., Lombardo, M. V., Bullmore, E. T., Baron-Cohen, S., et al. (2012). Brain anatomy and its relationship to behavior in adults with autism spectrum disorder: a multicenter magnetic resonance imaging study. Arch. Gen. Psychiatry 69, 195-209. doi: 10.1001/archgenpsychiatry.2011.1251

Estes, A., Shaw, D. W. W., Sparks, B. F., Friedman, S., Giedd, J. N., Dawson, G., et al. (2011). Basal ganglia morphometry and repetitive behavior in young children with autism spectrum disorder. Autism Res. 4, 212-220. doi: 10.1002/aur.193

Fair, D. A., Nigg, J. T., Iyer, S., Bathula, D., Mills, K. L., Dosenbach, N. U., et al. (2012). Distinct neural signatures detected for ADHD subtypes after controlling for micro-movements in resting state functional connectivity MRI data. Front Syst. Neurosci. 6:80. doi: 10.3389/fnsys.2012.00080

Finger, C. E., Marsh, A., Blair, K. S., Majestic, C., Evangelou, I. Gupta, K., et al. (2012). Impaired functional but preserved structural connectivity in limbic white matter tracts in youth with conduct disorder or oppositional defiant disorder plus psychopathic traits. Psychiatry Res. 202, 239-244. doi: 10.1016/j.pscychresns.2011.11.002

Frank, L. R. (2001). Anisotropy in high angular resolution diffusion-weighted MRI. Magn. Reson. Med. 45, 935-939. doi: 10.1002/mrm.1125

Frazier, W. T., Youngstrom, E. A., Kubu, C. S., Sinclair, L., and Rezai, A. (2008). Exploratory and confirmatory factor analysis of the autism diagnostic interview-revised. 
J. Autism Dev. Disord. 38, 474-480. doi: 10.1007/s10803-007-0415-z

Friston, K. J., Frith, C. D., Frackowiak, R. S., and Turner, R. (1995a). Characterizing dynamic brain responses with fMRI: a multivariate approach. Neuroimage 2, 166-172.

Friston, K. J., Frith, C. D., Turner, R., and Frackowiak, R. S. J. (1995b). Characterizing evoked hemodynamics with fMRI. Neuroimage 2, 157-165.

Gallagher, H. L., and Frith, C. D. (2003). Functional imaging of 'Theory of Mind'. Trends Cogn. Sci. 7, 77-83. doi: 10.1016/S1364-6613(02)00025-6

Georgiades, S., Szatmari, P., Boyle, M., Hanna, S., Duku, E., Zwaigenbaum, L., et al. (2012). Investigating phenotypic heterogeneity in children with autism spectrum disorder: a factor mixture modeling approach. J. Child Psychol. Psychiatry 54, 206-215. doi: 10.1111/j.1469-7610. 2012.02588.x

Goldman-Rakic, P. S., Cools, A. R., and Srivastava, K. (1996). The prefrontal landscape: implications of functional architecture for understanding human mentation and the central executive [and discussion]. Philos. Trans. R. Soc. Lond. B Biol. Sci. 351, 1445-1453. doi: 10.1098/rstb.1996.0129

Greimel, E., Nehrkorn, B., Fink, G. R., Kukolja, J., Kohls, G., Müller, K., et al. (2012a). Neural mechanisms of encoding social and Non-social context information in autism spectrum disorder. Neuropsychologia 50, 3440-3449. doi: 10.1016/j. neuropsychologia.2012.09.029

Greimel, E., Nehrkorn, B., SchulteRüther, M., Fink, G. R., NicklJockschat, T., Herpertz-Dahlmann, B., et al. (2012b). Changes in grey matter development in autism spectrum disorder. Brain Struct. Funct. 18, 929-942. doi: 10.1007/s00429012-0439-9

Greitz, D., Wirestam, R., Franck, A., Nordell, B., Thomsen, C., and Ståhlberg, F. (1992). Pulsatile brain movement and associated hydrodynamics studied by magnetic resonance phase imaging. The Monro-Kellie Doctrine revisited. Neuroradiology 34, 370-380. doi: 10.1007/BF00596493

Groen, W., Teluij, M., Buitelaar, J., and Tendolkar, I. (2010). Amygdala and hippocampus enlargement during adolescence in autism. J. Am. Acad. Child Adolesc. Psychiatry 49, 552-560.

Groenewegen, J. H., van den Heuvel, O. A., Cath, D. C., Voorn, P., and Veltman, D. J. (2003). Does an imbalance between the dorsal and ventral striatopallidal systems play a role in tourette's syndrome? A neuronal circuit approach. Brain Dev. 25(Suppl. 1), S3-S14. doi: 10.1016/S0387-7604(03)90001-5

Groenewegen, J. H., Wright, C. I., Beijer, A. V., and Voorn, P. (1999). Convergence and segregation of ventral striatal inputs and outputs. Ann. N.Y. Acad. Sci. 877, 49-63. doi: 10.1111/j.17496632.1999.tb09260.x

Haber, S. N. (2003). The primate basal ganglia: parallel and integrative networks. J. Chem. Neuroanat. 26, 317-330. doi: 10.1016/j.jchemneu.2003.10.003

Haber, S. N., and Knutson, B. (2009). The reward circuit: linking primate anatomy and human imaging. Neuropsychopharmacology 35, 4-26. doi: 10.1038/npp.2009.129

Hadjikhani, N., Joseph, R. M., Snyder, J., and Tager-Flusberg, H. (2006). Anatomical differences in the mirror neuron system and social cognition network in autism. Cereb. Cortex 16, 1276-1282. doi: 10.1093/cercor/bhj069

Haznedar, M. M., Buchsbaum, M. S., Wei, T. C., Hof, P. R., Cartwright, C., Bienstock, C. A., et al. (2000). Limbic circuitry in patients with autism spectrum disorders studied with positron emission tomography and magnetic resonance imaging. Am. J. Psychiatry 157, 1994-2001. doi: 10.1176/appi.ajp.157.12.1994

Herbert, M. R., Ziegler, D. A., Deutsch, C. K., O'Brien, L. M., Kennedy, D. N., Filipek, P. A., et al. (2005). Brain asymmetries in autism and developmental language disorder: a nested whole-brain analysis. Brain $128,213-226$.

Hollander, E., Anagnostou, E., Chaplin, W., Esposito, K., Mehmet Haznedar, M., Licalzi, E., et al. (2005). Striatal volume on magnetic resonance imaging and repetitive behaviors in autism. Biol. Psychiatry 58, 226-232. doi: 10.1016/j.biopsych.2005.03.040

Hyde, L. K., Samson, F., Evans, A. C., and Mottron, L. (2010). Neuroanatomical Differences in brain areas implicated in perceptual and other core features of autism revealed by cortical thickness analysis and voxel-based morphometry. Hum. Brain Mapp. 31, 556-566.

Jeurissen, B., Leemans, A., Tournier, J.-.D., Jones, D. K., and Sijbers, J. (2012). Investigating the prevalence of complex fiber configurations in white matter tissue with diffusion magnetic resonance imaging. Hum. Brain Mapp. doi: 10.1002/ hbm.22099. [Epub ahead of print].
Jones, D. K. (2010). Challenges and limitations of quantifying brain connectivity in vivo with diffusion MRI. Imaging 2, 341-355. doi 10.2217/iim.10.21

Joshi, G., Biederman, J., Wozniak, J. Goldin, R. L., Crowley, D., Furtak, S., et al. (2012). Magnetic resonance spectroscopy study of the glutamatergic system in adolescent males with high-functioning autistic disorder: a pilot study at 4T. Eur. Arch. Psychiatry Clin. Neurosci. doi 10.1007/s00406-012-0369-9. [Epub ahead of print].

Just, M. A., Cherkassky, V. L., Keller, T. A., Kana, R. K., and Minshew, N. J. (2007). Functional and anatomical cortical underconnectivity in autism: evidence from an fmri study of an executive function task and corpus callosum morphometry. Cereb. Cortex 17, 951-961. doi: 10.1093/cercor/bhl006

Just, M. A., Cherkassky, V. L., Keller, T. A., and Minshew, N. J. (2004). Cortical activation and synchronization during sentence comprehension in highfunctioning autism: evidence of underconnectivity. Brain J. Neurol. 127(Pt 8), 1811-1821. doi: 10.1093/brain/awh199

Kana, R. K., Keller, T. A., Cherkassky, V. L., Minshew, N. J., and Just, M. A. (2009). Atypical frontalposterior synchronization of theory of mind regions in autism during mental state attribution. Soc. Neurosci. 4, 135-152. doi 10.1080/17470910802198510

Keller, T. A., Kana, R. K., and Just, M. A. (2007). A developmental study of the structural integrity of white matter in autism. Neuroreport 18, 23-27. doi: 10.1097/01.wnr. 0000239965.21685.99

Kleinhans, N. M., Richards, T., Sterling, L., Stegbauer, K. C., Mahurin, R., Johnson, L. C., et al. (2008). Abnormal functional connectivity in autism spectrum disorders during face processing. Brain 131, 1000-1012. doi: 10.1093/brain/awm334

Kohls, G., Chevallier, C., Troiani, V., and Schultz, R. T. (2012a). Social 'Wanting' dysfunction in autism: neurobiological underpinnings and treatment implications. J. Neurodev. Disord. $4,10$.

Kohls, G., Schulte-Rüther, M., Nehrkorn, B., Müller, K., Fink, G. R., Kamp-Becker, I., et al. (2012b). Reward system dysfunction in autism spectrum disorders. Soc. Cogn. Affect. Neurosci. 8 565-572. doi: 10.1093/scan/nss033
Koshino, H., Carpenter, P. A., Minshew, N. J., Cherkassky, V. L., Keller, T. A., and Just, M. A. (2005). Functional connectivity in an fMRI working memory task in high-functioning autism. Neuroimage 24, 810-821. doi: 10.1016/j.neuroimage.2004.09.028

Langen, M., Durston, S., Kas, M. J. H., van Engeland, H., and Staal, W. G. (2011a). The neurobiology of repetitive behavior: ... and men. Neurosci. Biobehav. Rev. 35, 356-365.

Langen, M., Leemans, A., Johnston, P., Ecker, C., Daly, E., Murphy, C. M., et al. (2011b). Fronto-striatal circuitry and inhibitory control in autism: findings from diffusion tensor imaging tractography. Cortex 48 , 183-193. doi: 10.1016/j.cortex.2011. 05.018

Langen, M., Schnack, H. G., Nederveen, H., Bos, D., Lahuis, B. E., de Jonge, M. V., et al. (2009). Changes in the developmental trajectories of striatum in autism. Biol. Psychiatry 66, 327-333. doi: 10.1016/j.biopsych.2009.03.017

Lebel, C., Walker, L., Leemans, A., Phillips, L., and Beaulieu, C. (2008). Microstructural maturation of the human brain from childhood to adulthood. Neuroimage 40, 1044-1055. doi: 10.1016/j.neuroimage.2007.12.053

Leemans, A., Jeurissen, B., Sijbers, J., and Jones, D. K. (2009). "ExploreDTI: A graphical toolbox for processing, analyzing, and visualizing diffusion MR Data." in Presented at the Proceedings 17th Scientific Meeting, International Society for Magnetic Resonance in Medicine (Honolulu, HI).

Leemans, A., and Jones, D. K. (2009). The $\mathrm{B}$-matrix must be rotated when correcting for subject motion in DTI data. Magn. Reson. Med. 61, 1336-1349. doi: $10.1002 / \mathrm{mrm} .21890$

Leh, S. E., Ptito, A., Chakravarty, M. M., and Strafella, A. P. (2007). Fronto-striatal connections in the human brain: a probabilistic diffusion tractography study. Neurosci. Lett. 419, 113-118. doi: 10.1016/j.neulet.2007.04.049

Lehéricy, S., Ducros, M., Van De Moortele, P. F., Francois, C., Thivard, L., Poupon, C., et al. (2004). Diffusion tensor fiber tracking shows distinct corticostriatal circuits in humans. Ann. Neurol. 55, 522-529. doi: 10.1002/ana.20030

Leung, H.-C., Gore, J. C., and Goldman-Rakic, P. S. (2002). Sustained mnemonic response in the human middle frontal 
gyrus during on-line storage of spatial memoranda. J. Cogn. Neurosci. 14, 659-671. doi: 10.1162/08989290260045882

Limbrick-Oldfield, E. H., Brooks, J. C. W., Wise, R. J. S., Padormo, F., Hajnal, J. V., Beckmann, C. F., et al. (2012). Identification and characterisation of midbrain nuclei using optimised functional magnetic resonance imaging. Neuroimage 59, 1230-1238. doi: 10.1016/j.neuro image.2011.08.016

Liu, Y., Wang, K., Yu, C., He, Y., Zhou, Y., Liang, M., et al. (2008). Regional homogeneity, functional connectivity and imaging markers of Alzheimer's disease: a. review of resting-state fMRI studies. Neuropsychologia 46, 1648-1656. doi: $\quad 10.1016 /$ j.neuropsychologia. 2008.01.027

Lord, C., Rutter, M., DiLavore, P. C., and Risi, S. (2000). Autism diagnostic observation schedule (ADOS). J. Autism Dev. Disord. 30, 205-233. doi: 10.1023/A:1005592401947

Lord, C., Rutter, M., and Le Couteur, A. (1994). Autism diagnostic interview[mdash] revised: a revised version of a diagnostic interview for caregivers of individuals with possible pervasive developmental disorders. J. Autism Dev Disord 24, 659-685. doi: 10.1007/BF02172145

Luna, B., Minshew, N. J., Garver, K. E., Lazar, N. A., Thulborn, K. R., Eddy, W. F., et al. (2002). Neocortical system abnormalities in autism an fMRI study of spatial working memory. Neurology 59, 834-840. doi: 10.1212/WNL.59.6.834

Mak-Fan, K. M., Morris, D., Vidal, J., Anagnostou, E., Roberts, W., and Taylor, M. J. (2012). White matter and development in children with an autism spectrum disorder. Autism. doi: 10.1177/136236131244 2596. [Epub ahead of print]

Mandy, L. W. P., Charman, T., and Skuse, D. H. (2012). Testing the construct validity of proposed criteria for DSM-5 autism spectrum disorder. J. Am. Acad. Child Adolesc. Psychiatry 51, 41-50. doi: 10.1016/j.jaac.2011.10.013

Middleton, A. F., and Strick, P. L. (2000). Basal ganglia and cerebellar loops: motor and cognitive circuits. Brain Res. Brain Res. Rev. 31, 236-250. doi: 10.1016/S01650173(99)00040-5

Mizuno, A., Villalobos, M. E., Davies, M. M., Dahl, B. C., and Müller, R. (2006). Partially enhanced thalamocortical functional connectivity in autism. Brain Res. 1104, 160-174. doi: 10.1016/j.brainres.2006.05.064
Müller, R., Shih, P., Keehn, B., Deyoe, J. R., Leyden, K. M., and Shukla, D. K. (2011). Underconnected, but How? A survey of functional connectivity MRI studies in autism spectrum disorders. Cereb. Cortex 21, 2233-2243. doi: 10.1093/cercor/bhq296

Paakki, J., Rahko, J., Long, X., Moilanen, I., Tervonen, O., Nikkinen, J., et al. (2010). Alterations in regional homogeneity of resting-state brain activity in autism spectrum disorders. Brain Res. 1321, 169-179. doi: 10.1016/j.brainres.2009.12.081

Pasupathy, A., and Miller, E. K. (2005). Different time courses of learningrelated activity in the prefrontal cortex and striatum. Nature 433, 873-876. doi: 10.1038/nature03287

Power, D. J., Barnes, K. A., Snyder, A. Z., Schlaggar, B. L., and Petersen, S. E. (2012). Spurious but systematic correlations in functional connectivity MRI networks arise from subject motion. Neuroimage 59, 2142-2154. doi: 10.1016/j.neuroimage.2011.10.018

Raj, D. A., Anderson, W., and Gore, J. C. (2001). Respiratory effects in human functional magnetic resonance imaging due to bulk susceptibility changes. Phys. Med. Biol. 46, 3331-3340. doi: 10.1088/0031$9155 / 46 / 12 / 318$

Robinson, J. L., Laird, A. R., Glahn, D. C., Blangero, J., Sanghera, M. K., Pessoa, L., et al. (2012). The functional connectivity of the human caudate: an application of meta-analytic connectivity modeling with behavioral filtering. Neuroimage 60, 117-129. doi: 10.1016/j.neuroimage.2011.12.010

Rogers, D. R., Ramnani, N., Mackay, C. Wilson, J. L., Jezzard, P., Carter, C. S., et al. (2004). Distinct portions of anterior cingulate cortex and medial prefrontal cortex are activated by reward processing in separable phases of decision-making cognition. Biol. Psychiatry 55, 594-602. doi: 10.1016/j.biopsych.2003.11.012

Rojas, D., Peterson, E., Winterrowd, E. Reite, M., Rogers, S., and Tregellas, J. (2006). Regional gray matter volumetric changes in autism associated with social and repetitive behavior symptoms. BMC Psychiatry 6:56. doi: 10.1186/1471-244X-6-56

Rudie, J. D., Shehzad, Z., Hernandez, L. M., Colich, N. L., Bookheimer, S. Y., Iacoboni, M., et al. (2011). Reduced functional integration and segregation of distributed neural systems underlying social and emotional information processing in autism spectrum disorders. Cereb. Cortex
22, 1025-1037. doi: 10.1093/cercor/ bhr171

Rushworth, M. F. S., Noonan, M. P., Boorman, E. D., Walton, M. E., and Behrens, T. E. (2011). Frontal cortex and reward-guided learning and decision-making. Neuron 70, 1054-1069. doi: 10.1016/j.neuron.2011.05.014

Rutter, M., Bailey, A., and Lord, C. (2003). Social Communication Questionnaire. Los Angeles, CA Western Psychological Services.

Sato, W., Toichi, M., Uono, S., and Kochiyama, T. (2012). Impaired social brain network for processing dynamic facial expressions in autism spectrum disorders. BMC Neurosci. 13:99. doi: 10.1186/14712202-13-99

Satterthwaite, T. D., Elliott, M A., Gerraty, R. T., Ruparel, K., Loughead, J., Calkins, M. E., et al. (2013). An improved framework for confound regression and filtering for control of motion artifact in the preprocessing of restingstate functional connectivity data. Neuroimage 64, 240-256. doi: 10.1016/j.neuroimage.2012.08.052

Schmitz, N., Rubia, K., Daly, E., Smith A., Williams, S., and Murphy, D. G. M. (2006). Neural correlates of executive function in autistic spectrum disorders. Biol. Psychiatry 59, 7-16. doi: 10.1016/j.biopsych.2005.06.007

Schultz, R. T. (2005). Developmental deficits in social perception in autism: the role of the amygdala and fusiform face area. Int. J. Dev. Neurosci. 23, 125-141. doi 10.1016/j.ijdevneu.2004.12.012

Schultz, W., Dayan, P., and Montague, P. R. (1997). A neural substrate of prediction and reward. Science 275, 1593-1599. doi: 10.1126/science.275.5306.1593

Takarae, Y., Minshew, N. J. Luna, B., and Sweeney, J. A. (2007). Atypical involvement of frontostriatal systems during sensorimotor control in autism. Psychiatry Res. 156, 117-127. doi: 10.1016/j.pscychresns.2007.03.008

Tuch, D. S. (2004). Q-ball Imaging. Magn. Reson. Med. 52, 1358-1372. doi: 10.1002/mrm.20279

Turner, K. C., Frost, L., Linsenbardt, D., McIlroy, J. R., and Müller, R. (2006). Atypically diffuse functional connectivity between caudate nuclei and cerebral cortex in autism. Behav. Brain Funct. 2, 34.

Tziortzi, A. C., Haber, S. N., Searle, G. E., Tsoumpas, C., Long, C. J., Shotbolt, P., et al. (2013). Connectivity-based functional analysis of dopamine release in the striatum using diffusion-weighted MRI and positron emission tomography. Cereb. Cortex. doi: 10.1093/ cercor/bhs397. [Epub ahead of print].

Van Dijk, A. K. R., Sabuncu, M. R., and Buckner, R. L. (2012) The influence of head motion on intrinsic functional connectivity MRI. Neuroimage 59, 431-438. doi: 10.1016/j.neuroimage.2011.07.044

Scott-Van Zeeland, K., McNealy, K., Wang, A. T., Sigman, M., Bookheimer, S. Y., and Dapretto, M. (2010). No neural evidence of statistical learning during exposure to artificial languages in children with autism spectrum disorders. Biol. Psychiatry 68, 345-351. doi: 10.1016/j.biopsych.2010.01.011

Vaidya, J. C., Foss-Feig, J., Shook, D., Kaplan, L., Kenworthy, L., and Gaillard, W. D. (2011). Controlling attention to gaze and arrows in childhood: an fMRI. study of typical development and autism spectrum disorders. Dev. Sci. 14, 911-924. doi: 10.1111/j.1467-7687. 2011.01041.x

Verhoeven, J., De Cock, P., Lagae, L., and Sunaert, S. (2009). Neuroimaging of autism. Neuroradiology 52, 3-14. doi: 10.1007/s00234-009-0583-y

Verhoeven, S. J., Sage, C. A., Leemans, A., Van Hecke, W., Callaert, D., Peeters, R., et al. (2010). Construction of a stereotaxic DTI atlas with full diffusion tensor information for studying white matter maturation from childhood to adolescence using tractographybased segmentations. Hum. Brain Mapp. 31, 470-486.

Verstynen, D. T., Badre, D. Jarbo, K., and Schneider, W. (2012). Microstructural organizational patterns in the human corticostriatal system. J. Neurophysiol. 107, 2984-2995. doi: 10.1152/jn.00995.2011

Vogt, B. A. (2005). Pain and emotion interactions in subregions of the cingulate gyrus. Nature Rev. Neurosci. 6, 533-544. doi: 10.1038/nrn1704

Von dem Hagen, E. A., Stoyanova, R. S., Baron-Cohen, S., and Calder, A. J. (2012). Reduced functional connectivity within and between 'social' resting state networks in autism spectrum conditions. Soc. Cogn. Affect. Neurosci. doi: 10.1093/ scan/nss053. [Epub ahead of print].

Vos, B. S., Jones, D. K., Jeurissen, B. Viergever, M. A., and Leemans, A. (2012). The influence of complex white matter architecture on the 
mean diffusivity in diffusion tensor MRI of the human brain. Neuroimage 59, 2208-2216. doi: 10.1016/j.neuroimage.2011.09.086

Walter, H., Abler, B., Ciaramidaro, A., and Erk, S. (2005). Motivating forces of human actions. Neuroimaging reward and social interaction. Brain Res. Bull. 67, 368-381. doi: 10.1016/j.brainres bull.2005.06.016

Walter, H., Adenzato, M., Ciaramidaro, A., Enrici, I., Pia, L., and Bara, B. G. (2004). Understanding intentions in social interaction: the role of the anterior paracingulate cortex. J. Cogn. Neurosci. 16, 1854-1863. doi: 10.1162/0898929042947838

Watanabe, H., Nakamura, M., Ohno, T., Itahashi, T., Tanaka, E., Ohta, H., et al. (2013). Altered orbitofrontal sulcogyral patterns in adult males with high-functioning autism spectrum disorders. Soc. Cogn.
Affect. Neurosci. doi: 10.1093/scan/ nst016. [Epub ahead of print].

Wechsler, D. (1999). Wechsler Abbreviated Scale of Intelligence. San Antonio, TX: The Psychological Corporation.

Wechsler, D. (2003). Wechsler Intelligence Scale for Children, 4th Edn (WISC-IV). San antonio, TX: The Psychological Corporation. Weng, S. J., Wiggins, J. L., Peltier, S. J., Carrasco, M., Risi, S., Lord, C., et al. (2010). Alterations of resting state functional connectivity in the default network in adolescents with autism spectrum disorders. Brain Res. 1313, 202-214. doi: 10.1016/j.brainres. 2009.11.057

Whitfield-Gabrieli, S., and NietoCastanon, A. (2012). Conn: a functional connectivity toolbox for correlated and anticorrelated brain networks. Brain
Connect. 2, 125-141. doi: 10.1089/brain.2012.0073

Yan, C. G., Cheung, B., Kelly, C., Colcombe, S., Craddock, R. C., Di Martino, A., et al. (2013). A comprehensive assessment of regional variation in the impact of head micromovements on functional connectomics. Neuroimage 76, 183-201. doi: 10.1016/j.neuroimage.2013.03.004

Yeterian, E. H., Pandya, D. N., Tomaiuolo, F., and Petrides, M. (2012). The cortical connectivity of the prefrontal cortex in the monkey brain. Cortex 48, 58-81. doi: 10.1016/j.cortex.2011.03.004

Conflict of Interest Statement: The authors declare that the research was conducted in the absence of any commercial or financial relationships that could be construed as a potential conflict of interest.
Received: 25 February 2013; accepted: 15 July 2013; published online: 06 August 2013.

Citation: Delmonte S, Gallagher L, O'Hanlon E, McGrath $J$ and Balsters JH (2013) Functional and structural connectivity of frontostriatal circuitry in Autism Spectrum Disorder. Front. Hum. Neurosci. 7:430. doi: 10.3389/fnhum. 2013.00430

Copyright (C) 2013 Delmonte, Gallagher, O'Hanlon, McGrath and Balsters. This is an open-access article distributed under the terms of the Creative Commons Attribution License (CC BY). The use, distribution or reproduction in other forums is permitted, provided the original author(s) or licensor are credited and that the original publication in this journal is cited, in accordance with accepted academic practice. No use, distribution or reproduction is permitted which does not comply with these terms. 